\title{
EDITORIAL
}

\section{A perspective on seismology in India}

Dr Vinod Gaur kindly asked me to be a guest editor for a special issue of the Proceedings of the Indian Academy of Sciences to be focussed on seismology in India. We selected a number of prospective topics and authors and I began negotiations for contributions. The result is the group of excellent papers in this volume. I made no etfort toward a comprehensive coverage of seismology, but rather attempted to choose topics illustrative of a range of problems related to India. Thus many important topics (e.g. induced seismicity) are not represented. Some invited authors were unable to contribute, and probably others should have been invited to represent their topics, but the press of time and schedule, mostly on my part, made this impossible. I apologize to all those who could have made valuable contributions to this volume. The paper by Royer $e t$ al on the tectonic fabric of the Indian Ocean is not strictly seismological, but provides an important background for seismological interpretation, especially with regard to the structure in the Bay of Bengal. Many may feel that the authorship is too heavily weighted with scientists from outside India, and thus the overall perspective tends more to that of an outsider, and I would not disagree with this evaluation, but I am nevertheless hopeful that the volume will be stimulating to seismologists both inside and outside India. I would like to thank Dr Kailash Khattri for reviewing some of the contributions for me.

I began my career in seismology during the IGY (International Geophysical Year), an international programme which led to the installation of modern seismographs worldwide, and provided the data for my thesis. Thus I am very aware of the importance of international co-operative projects in seismology. The continuing benefit of such projects is illustrated by the strong motion data now being collected in India as a result of the Hawaii International Workshop on Strong Motion Arrays (1978), which stimulated arrays in India, Taiwan, Mexico, China, the U.S., and Turkey (see the article on strong motion seismology in this volume). The importance of such arrays is graphically emphasized by the recent damaging earthquake in the India-Nepal border region. Recognition of the importance of international cooperative projects is most recently illustrated by the plans for the International Decade of Natural Hazard Reduction, including an important meeting to be held in New Delhi in the summer of 1989 . Of course national efforts in research will usually take priority over international efforts, however, möst nations are realizing that international co-operative projects are crucial to their own national development.

The problems inherent in developing international co-operative projects illustrate some basic problems in research and I would like to share some of my views on these, based on my years of fruitful co-operative research in Mexico and my more recent visits to India.

As a scientific discipline seismology has developed from a young science to a mature science. The characteristics of the types of research programmes have changed, and 
consequently so have the requirements for both international co-operative research and purely national research. Many of us can remember when discoveries in seismology were simple and inexpensive, and contrast that situation with the current situation where much of the funding for seismology is for large multi-institutional projects.

When seismology was young, major discoveries, causing qualitatively great changes in our understanding, were made relatively simply by a few dedicated "basic" researchers and students, with minimal funding support. Research was carried out with individually constructed equipment and simple calculations using elementary first-order theory inspired by physical intuition. The individual scientist struggling to advance his own career, automatically helped other scientists advance their careers, and promoted the rapid advancement of science. Examples of discoveries during this stage include discoveries of the Mohorovicic discontinuity, the earth's core and general structure, surface wave dispersion, the double-couple earthquake mechanism, free oscillations of the earth, and of course, plate tectonics.

Seismology has now matured in many respects. Emphasis is on relatively small improvements in quantitative knowledge, and eliminating non-uniqueness in sophisticated theoretical models. These are brought about only with great difficulty by teams of scientists and technicians, many with an applied research and management orientation. There is a relatively great expenditure of money for small improvements in accuracy, with the research direction dictated by societal goals and relevance (e.g. nuclear test detection, and earthquake hazard reduction). The tools are standardized accurately calibrated commercial equipment, sophisticated higher order theoretical calculations requiring great mathematical skill and large computers, with relatively less reliance on intuition. If developing countries are to fully contribute they need to participate in multidisciplinary, multinational, mission-oriented projects, and need to be willing to invest the relatively large amounts of time and money required. Examples of such projects include large seismic arrays such as NORSAR and the Gauribidanur array, the worldwide seismograph network, strong motion arrays, multidisciplinary and multi-institutional ocean-going surveys, IRIS (Incorporated Research Institutions for Seismology) and PASSCAL (Program for Array Seismic Studies of the Continental Lithosphere). These projects usually result in papers with several co-authors.

As we are all aware, at this stage politics may play an important role. Large international or bi-national projects can impact a nation economically and militarily. Research can lead to unexpected results, and politicians are reluctant to commit national efforts and funds to projects which they do not understand and fear may affect them adversely. As a consequence, important research which could help a nation is not carried out. An excellent example might be the seismic hazard research in the Himalayas, which could obviously benefit millions of people, but which unfortunately is hampered by border security concerns. Because of the uniqueness of the Himalayan region, understanding the earth structure, tectonics, earthquake mechanism and wave propagation in that region could be of great importance to the international community, and in particular to the objectives of the International Decade of Natural Hazard Reduction.

There are strong incentives for government agencies to fund international co-operative projects e.g. national, economical and political advancement, national hazard reduction, increasing the national educational level, and, last but not least, 
development of basic research capabilities. In the long run basic research will help all of the above objectives, but in the short run is often considered too costly a drain on resources for attacking more immediate social problems.

The career advancement of individual investigators, students, and technicians is one of the motivating factors behind co-operative research. Priorities must be balanced between, on the one hand, publishing results as soon as possible, and on the other hand allowing students and other apprentices to take the initiative on important problems in order to learn more effectively. There is the obvious scientific incentive of publishing as soon as possible. On the other hand, "hot" research projects are usually best for teaching students because they help develop enthusiasm and competence which will last into the future. Students and apprentices are less experienced and often take longer to work up data and finish research. A wise balance is required in these matters in order to maximize the short and long-term benefits to both the nation and the international community.

Of course military and economic interests often interfere with co-operative research. I will not discuss this obvious and much analysed problem except to observe that the United Nations has been much less effective in helping the situation than I and many others had hoped 20 years ago. We may hope that time will slowly improve the problem.

The problems discussed above have general relevance to India. As far as seismology in particular is concerned, the two problems I have had some experience with are study of the crustal structure in the Bay of Bengal, and attempting to share co-operative seismic source mechanism and hazard projects in the Himalayas. Both have been effected by such difficulties. Both the Himalayan tectonic belt and the Bengal sedimentary basin are unique and the largest examples of their type on our planet, and thus attract high interest. They are of obvious military and economic sensitivity. Naturally Indian researchers would like to have the funding support to attack these problems themselves. And, because of their uniqueness, they are also of great importance to the international community and consequently there is strong incentive to attempt to initiate co-operative field and sea-going operations. One would hope that some way would be found to overcome the difficulties involved with such co-operative research in such a way that all parties would benefit.

A specific problem in seismology is the lack of facilities and incentives to make data, especially early data, available to interested researchers. Again two incentives are at work. On the one hand there is the incentive to get the research done as soon as possible because it would provide answers to scientific problems important to the nation. From this point of view one would like to have the data made as widely available as possible, to both national and international researchers. On the other hand this policy would entail many of the real or perceived national and personal risks touched on above. To mention one, if other researchers use the data to make all of the exciting discoveries, this will deprive the students and personnel of the institution in charge of the data of the opportunity for making the discoveries themselves, and thus advancing their own careers. A wise balance would be to make sure that the institution in charge of the data has both an incentive for co-operation and adequate facilities and funding to co-operate with others on an equal basis.

As far as academic preparation for research is concerned, I feel that all the mechanisms for the high level training, required are potentially in place in India. What may be to a certain extent lacking is team organization and "critical mass" groups 
necessary to be fully effective in the modern age of complex multidisciplinary research. The isolated "ivory tower" scientist is obviously still important, however there is no reason that such a person cannot be associated with an applied research group so that valuable cross-fertilization of ideas can occur. This cross-fertilization is difficult if the scientist is the only one of his field at a spatially isolated university, even if that university is of high academic quality.

Government research groups are obviously critical in modern research, but I feel they could be more effective if there was a closer tie with nearby academic institutions. Graduate student research and training, along with the natural energy and enthusiasm of students is important to stimulating fundamental research at these centers.

\section{The future}

As an old saying goes: "The future is upon us". This is certainly true in seismology with the advent of exploding computing power, rapid data transmission capabilities, greatly improved instruments, modern techniques of analysis of digital data, and rapidly improving transportation and logistical facilities. I believe the way of the future is toward standardized data collection techniques. A critical loss of efficiency will result without this standardization. A recent publication of the U.S. National Academy Press (1988) "Geophysical data: Policy issues", graphically points out the fact that a tremendous amount of valuable data, collected at considerable cost, is not actually available because of the lack of standardization of formats. This is natural in the early stages of development of a scientific field, but should be corrected as a field develops. The report recommends that a series of guidelines and policies be adopted to correct the situation and to make future data more easily accessible and useful. As for many of the issues discussed above, international co-operation will be critical in this regard. Formats should be standardized as soon as possible so that scientists in developing countries will have easy access to the modern data, and to modern data analysis techniques. Data collected at considerable public expense cannot be "locked up" because only one or two scientists or technicians have the facilities and knowledge to use it. especially when this data may relate to such issues as seismic safety and national economic development.

India currently has the capability of carrying out state-of-the-art research on determination of earth structure, and the primary challenge of the future will be setting priorities in funding, based on the economic benefit of such studies. Determination of earth structure can be of great importance to mineral exploration and seismic hazard reduction. Passive continental margins, the Bengal Fan, and the Indus Fan have great economic potential, and determination of regional and deep crustal structure using seismic means may aid local exploration efforts. There may be some benefit to international co-operative studies in the deeper water parts of these structures.

It is obvious that India, with such a high population concentration in the Himalayan seismic region, will have to devote a major effort to seismic hazard research in the next decade. The major thrust of this will have to be toward: (i) defining the actual seismic hazard in India (e.g. through seismicity studies, geologic studies of recent fault motion, refined estimates of probability, measurement of Fourier spectra 
and response spectra of earthquakes, determination of local ground motion amplification), and (ii) clarifying the various options for confronting these hazards (specifically involving cost-benefit analysis). The importance of such studies is highlighted by the controversy over the seismic hazard to Tehri Dam, a construction project of tremendous potential benefit to India, and at the same time of tremendous potential devastation if it should fail during the great earthquake expected in the region. In spite of such tremendous importance to India, knowledge of the tectonics and seismology of the region is only primitive, but could be greatly improved within a few years with modern instrumentation and geological studies.

Some specific critical decisions relating to seismology in India will probably need to be made in the next few years, or perhaps even in the next few months:

(i) Should a modern standardized national seismic system, both for strong and weak motion recording, be established?

(ii) How much effort should be made to integrate seismic data systems with those of the international community?

(iii) Shou!d data transmission be primarily by satellite, with event recording, or should part of the national array have continuous recording, perhaps with microwave transmission?

(iv) How much emphasis should be placed on PC computer facilities for individual scientists, versus emphasis on large centralized facilities for data analysis and theoretical computations?

(v) How much emphasis should be placed on small research grants to individual investigators, versus support for large multidisciplinary, multi-institutional projects?

(vi) How much effort and expense should be put into earthquake resistant building design?

(vii) How much effort should be put into short-term earthquake prediction and earthquake warning systems?

Most of these issues are common to many other nations. In order to expedite the decision-making process, I would recommend that a high-level panel or commission be set up to make recommendations to the government on the above issues.

In conclusion, I feel that seismology in India is at the threshold of a most interesting and challenging period. The rewards for correct policy decisions can be great, but the consequences of error can be disastrous. India has the national capability to successfully attack these problems by itself, but the most cost-effective strategy would probably be to participate as fully as possible in future international co-operative projects such as the International Decade of Natural Hazard Reduction.

Department of Geological Sciences

Mackay School of Mines

James N. Brune

University of Reno

Guest Editor

Reno, Nevada 89557, USA 